\title{
HIV and smoking: associated risks and prevention strategies
}

This article was published in the following Dove Press journal:

HIVIAIDS - Research and Palliative Care

24 December 2015

Number of times this article has been viewed

\author{
Wanjiku Kariuki' \\ Jennifer I Manuel ${ }^{2}$ \\ Ngaruiya Kariuki ${ }^{3}$ \\ Ellen Tuchman ${ }^{2}$ \\ Johnnie O'Neal ${ }^{4}$ \\ Genevieve A Lalanne ${ }^{2}$ \\ 'University of Texas School of Public \\ Health, Department of Management, \\ Policy, and Community Health, \\ Houston, TX, ${ }^{2}$ Silver School of Social \\ Work, New York University, New \\ York, Internal Medicine Department, \\ Maimonides Medical Center, Brooklyn, \\ ${ }^{4}$ Department of Social Work, The \\ College of New Rochelle, New \\ Rochelle, NY, USA
}

\begin{abstract}
High rates of smoking among persons living with HIV (PLWH) may reduce the effectiveness of HIV treatment and contribute to significant morbidity and mortality. Factors associated with smoking in PLWH include mental health comorbidity, alcohol and drug use, health-related quality of life, smoking among social networks and supports, and lack of access to care. PLWH smokers are at a higher risk of numerous HIV-associated infections and non-HIV related morbidity, including a decreased response to antiretroviral treatment, impaired immune functioning, reduced cognitive functioning, decreased lung functioning, and cardiovascular disease. Seventeen smoking cessation interventions were identified, of which seven were randomized controlled trials. The most effective studies combined behavioral and pharmacotherapy treatments that incorporated comprehensive assessments, multiple sessions, and cognitive-behavioral and motivational strategies. Smoking cessation interventions that are tailored to the unique needs of diverse samples and incorporate strategies to reduce the risk of relapse are essential to advancing health outcomes in PLWH.
\end{abstract}

Keywords: HIV, AIDS, smoking, health risks, smoking cessation interventions

\section{Introduction}

Cigarette smoking is one of the leading preventable risk factors contributing to morbidity and mortality in the US. ${ }^{1}$ While smoking rates in the US general population are $19 \%$, the rate of smoking among persons living with HIV (PLWH) is estimated to be two to three times higher, with recent estimates over $40 \% .^{2-4}$ Among PLWH, over $85 \%$ are estimated to have a lifetime history of smoking. ${ }^{5}$ PLWH with a lifetime history of smoking are half as likely to be abstinent from smoking compared to the general population. ${ }^{6}$ On average, HIV+ smokers use $16-23$ cigarettes per day ${ }^{7,8}$ and have been smoking almost 23 years, ${ }^{5}$ suggesting a high risk for nicotine dependence in this population.

In recent years, advances in the treatment of HIV have improved immune function in HIV+ individuals. However, the health-related risks associated with smoking may diminish the benefits of HIV treatment. ${ }^{3}$ The average years of life lost among HIV+ individuals due to smoking is 12.3 years, which is more than twice that in the general population. ${ }^{9}$ With medical costs exceeding US\$96 billion per year, ${ }^{10}$ public health professionals recognize the significant burden of smoking and have made smoking cessation a high priority. ${ }^{11}$ The overall goal of this article is to review the associated risks and smoking cessation strategies for HIV+ persons. First, we examine the health risks and outcomes that smoking can cause in this population, including HIV- and non-HIV related morbidity and mortality. Second, given the high rates of smoking
Correspondence: Jennifer I Manuel Silver School of Social Work, New York University, I Washington Square North, New York, NY 10003, USA

Tel +l 2129985972

Fax +19175910818

Email jennifer.manuel@nyu.edu 
and health risks, we review the existing evidence on smoking cessation strategies designed for HIV+ individuals. Finally, we discuss the limitations of the existing literature and offer recommendations for future research.

\section{Health risks and outcomes Effect of smoking on HIV acquisition and disease progression}

There are conflicting data on whether tobacco smoking alters HIV disease susceptibility, HIV disease progression, or if there are unique health consequences related to smoking in the context of HIV+ status.

In the past, inquiry into the association between cigarette smoking and the acquisition of HIV infection has resulted in much dispute with some researchers arguing that cigarette smoking is associated with a statistically significant increase in the incidence of HIV seroconversion. ${ }^{12}$ In support of this statistical association is immunological evidence that tobacco smoke can enhance HIV infectivity possibly by a combination of direct (antioxidant) and indirect (gene-based) mechanisms. ${ }^{13}$ Analogously, a study by Zhao et al ${ }^{13}$ concluded that "tobacco smoke extract up-regulates some genes known to be capable of enhancing HIV infection, or protecting HIV, but down-regulates several genes involved in cellular defense and antigen presentation".

Moreover, though the general consensus is that smokers have higher baseline CD4+ counts compared with nonsmokers, ${ }^{14}$ some of the literature ${ }^{15,16}$ documents rapid CD4 cell count falloffs among tobacco users signifying a possible correlation between smoking and HIV disease progression. ${ }^{14}$ In support of this theory is an immunological study by Valiathan et al, ${ }^{17}$ which concluded that cigarette smoking has a quantifiable deleterious impact on immune activation, gut microbial translocation, immune exhaustion, and T cell function in HIV-infected individuals. ${ }^{17}$ In both HIV+ and HIV-study participants, smokers had higher cellular markers of CD4+ and CD8+ $\mathrm{T}$ cell activation, higher gut microbial translocation, increased levels of CD4+ $\mathrm{T}$ cell immune exhaustion, and impaired function of CD4+ and CD8+ T cells. ${ }^{17}$ Accordingly, these observations led the investigators to conclude that "smoking and HIV infection independently influence $\mathrm{T}$ cell immune activation and function and together they present the worst immune profile" hence the suggestion of a cumulative effect of smoking on the impairment of the immune system and accelerated disease progression. ${ }^{17}$

Similarly, cigarette smoking appears to mitigate the effects of highly active anti-retroviral therapy (HAART). A study by
Feldman et al $^{16}$ concluded that HAART was less effective in terms of reducing mortality and AIDS incidence among smokers compared to non-smokers, even after their results were adjusted for confounding factors including medication compliance and concurrent illicit drug use. Their results revealed lower CD4 counts and higher viral loads among smokers compared to non-smokers, equating to an inferior immune response and a higher probability of virologic rebound. ${ }^{16}$

Conversely, Marshall et $\mathrm{al}^{14}$ postulate that smoking does not accelerate disease progression to clinical AIDS but enhances susceptibility to HIV or other infections and modifies the risk associated with smoking-related chronic diseases. The counterargument provided by Marshall et al is that many of the studies purporting a statistical correlation between smoking status and HIV disease progression are prone to sample bias, particularly homogeneity - studies of only women, men who have sex with men (MSM), or injection drug users - hence possible confounding of results. ${ }^{14}$

Notably, there are some unique and unforeseen health consequences of cigarette smoking habits among the HIV+ population. One such consequence is an inverse relationship between current smoking status and AIDS-related Kaposi's sarcoma. ${ }^{18}$ Hoover et $\mathrm{al}^{19}$ theorized that smoking induces inflammatory cytokines that reduce the risk of AIDSassociated Kaposi's sarcoma. Luu et $\mathrm{a}^{18}$ further expounded on this theory to incorporate the independent effect of HAART on reducing Kaposi's sarcoma risk and concluded that the protective effect of cigarette smoking against Kaposi's sarcoma risk is limited to those not receiving HAART. Furthermore, there is a higher incidence of other HIV-associated malignancies, including cancer of anus, cervix, lip, mouth, and pharynx, among smokers compared to non-smokers. ${ }^{20-22}$ This in turn may be explained by the higher viral load of the human papilloma virus strains responsible for these diseases (human papilloma virus types 16 and 18) that have been observed in HIV+ smokers. ${ }^{23,24}$

\section{Effect of smoking on non-AIDS related morbidity in PLWH}

\section{Comorbid mental health disorders and substance use}

PLWH have higher rates of co-occurring mental health problems and alcohol and drug use than non-HIV infected individuals. ${ }^{25,26}$ In a study of $60 \mathrm{HIV}+$ smokers, Shuter et $\mathrm{al}^{27}$ found that $73.3 \%$ and $61.7 \%$ of the participants had depression or anxiety, respectively. Most participants reported that smoking was used as a way to cope with their depression or anxiety. Mdodo et $\mathrm{al}^{28}$ used the Medical Monitoring Project 
and the National Health Interview Survey to examine HIV and smoking in a nationally representative sample of US adults and found that HIV+ individuals were more likely to be depressed $(\mathrm{N}=31,948)$ and use alcohol and illicit drugs than HIV- individuals. In a study of $200 \mathrm{HIV}+$ military veterans (smoking $\mathrm{N}=103$ ), Reisen et $\mathrm{al}^{29}$ found a significant connection between current smoking and depression and suggest that there is greater dependency on smoking among those who are depressed.

\section{Cognitive functioning}

In the general population, long-term cigarette dependence has been proven to be detrimental to global cognitive functioning, cognitive flexibility, and an increased likelihood of cognitive impairment. ${ }^{30}$ A similar association is present among the $\mathrm{HIV}+$ population whereby current smoking status is associated with reduced learning memory and decreased cognition, particularly among HIV+ male smokers. ${ }^{30}$ However, the interaction between HIV exposure and cigarette smoking exposure upon cognition and the mechanism of action between these exposures and neurocognitive outcomes is unclear. One study of PLWH with alcohol dependence suggests that both direct cytotoxicity to neuronal and glial cells and indirect effects of chronic tobacco use on comorbidities such as obesity and insulin resistance, which are themselves positively associated with neurocognitive impairment, generated an additional encumbrance on the integrity of brain neurobiology and neurocognition. ${ }^{31}$ However, the sample upon which this theory is based is comprised of HIV+ smokers who were also alcohol-dependent, and did not account for smoking duration or intensity. ${ }^{31}$ Overall, more study is required to clarify the pathway between exposures - HIV, smoking, substance dependence - and neurocognitive outcomes and the interaction of different exposures.

\section{Pulmonary function and pulmonary diseases}

Within both the general and HIV+ population, cumulative cigarette exposure is associated with decreased lung function. ${ }^{32}$ Moreover, given that smoking prevalence among the HIV+ population is thrice that of the general population, ${ }^{31}$ it is not surprising that the incidence of lung function compromise is greater within the HIV population. What remains to be determined is whether smoking decreases lung function more in HIV+ subjects compared to HIV-smokers sampled from the general population. While few studies exist to fully answer this query, one cross-sectional study ${ }^{32}$ found that spirometry findings, specifically forced expiratory volumes, are comparable to those of the general HIV- smoking population. Furthermore, both HIV+ and HIV- smokers experience similar levels of decline in lung function and thus there is no surplus or accelerated decline in the lung function of HIV+ smokers compared with published reference ranges for the general population. ${ }^{32}$

A cross-sectional study by Cui et $\mathrm{al}^{32}$ found that the odds of respiratory symptoms - cough, sputum production, and breathlessness - were higher in current smokers than nonsmokers, while former smokers had equivalent odds of respiratory symptoms as non-smokers, which implies possible advantages in initiating cessation therapy for HIV+ smokers regardless of smoking duration or intensity. Nevertheless, prior or current smoking history in HIV-infected persons raises susceptibility to several lung diseases that occur concurrently or in sequence, including tuberculosis, recurrent bacterial pneumonia, COPD, and influenza. ${ }^{33}$ The particular convergence of these lung diseases exacerbates pulmonary function, respiratory symptoms, and the severity of respiratory diseases. For instance, smoking causes long-term damage to pulmonary structures compromising respiratory function, which in the context of HIV immunosuppression leads to an accelerated form of COPD. ${ }^{34}$ This obstruction of respiratory passages predisposes to influenza that in turn increases the risk of contracting recurrent bacterial pneumonias, which in the immunocompromised increases susceptibility to further bacterial colonization including the risk of tuberculosis, and increases the likelihood of developing lung cancer.

A review of the epidemiologic data indicates that, controlling for cigarette smoking, the prevalence of lung cancer is two to four times greater in the HIV+ population than in the general population. ${ }^{35}$ Lung cancer is the most frequent non-AIDs associated tumor in HIV+ patients, and overall the third most common malignancy, preceded only by Kaposi's sarcoma and non-Hodgkin lymphoma. ${ }^{35}$ Perceptibly, lung cancer prevalence rates are only further compounded by the predominance of cigarette dependence within the HIV+ population and the success of antiretroviral therapy in prolonging life expectancies. Nonetheless, it has been observed that HIV+ patients who develop lung cancer are often severely immunosuppressed with very low CD4+ T cell counts, have a history of prior opportunistic lung disease, especially recurrent pneumonias, and clinical progression to AIDS. ${ }^{35}$ Notably, adenocarcinoma is the most frequent lung cancer histological cell type among $\mathrm{HIV}+$ cohorts, which is dissimilar to the general population in which squamous cell carcinoma histological subtype is more predominant and adenocarcinoma accounts for $13 \%$ of cases. ${ }^{35}$ 


\section{Coronary heart disease}

HIV infection and smoking are independent risk factors for coronary heart disease including acute myocardial infarction. The proposed pathogenesis involves a complex mechanism that entails inflammatory factors and immune dysfunction. Smoking cessation has been suggested as the single most important intervention to curb this risk. ${ }^{36}$

\section{Health-related quality of life}

With the classification of HIV changing from terminal to chronic, health-related quality of life (HRQOL) has become an interest to researchers. ${ }^{37}$ Unfortunately, relatively little is known about the effect of smoking on HRQOL among HIV+ persons. In a comprehensive literature review, Degroote et $\mathrm{l}^{38}$ identified 49 studies focusing on HIV+ HRQOL. They found no agreed-upon list of criteria for HRQOL and identified four categories: socio-demographic, clinical, psychological, and behavioral - which are relevant to smoking. In their review, the authors conclude that smoking has a negative influence on the quality of life of HIV+ adults. In fact, they found that smoking is harmfully linked with many of the factors discussed thus far. A 2011 report by Rahmanian et al ${ }^{39}$ cites two large studies that focused on HRQOL among HIV+ and HIV-adults. The first study by Turner et $\mathrm{a}^{39}(\mathrm{~N}=585)$ found decreased scores in perceptions of health, physical, and cognitive functioning, and physical pain among individuals with HIV. The second study by Crothers et $\mathrm{al}^{2}(\mathrm{~N}=1,773)$ was a veteran's affairs study of 1,034 HIV+ and $739 \mathrm{HIV}-$ adults. The researchers concluded the HRQOL for HIV+ adults is significantly lower than their HIV - counterparts. The authors also found that HIV+ adults were more likely to be current smokers, report injection drug use, and have a hepatitis C diagnosis. $^{2}$

\section{Mortality attributable to smoking among PLWH}

Although HIV-infected individuals with access to HAART are living longer, cigarette smoking habits still contribute to excess morbidity and mortality within this population. A retrospective cohort study ${ }^{40}$ of $\mathrm{HIV}+$ subjects found that compared to never smokers, current and past smokers with increased dose and or duration of smoking were at greater risk of all-cause mortality. ${ }^{2,40}$ However, all-cause mortality is halved in previous smokers compared to current smokers. ${ }^{9}$ Additionally, controlling for quality and access to health care and antiretroviral therapy, the data indicates that within HIV+ cohorts, the loss of life-years attributable to smoking is larger than that associated with
HIV. ${ }^{9}$ The excess mortality of smokers is tripled and the population-attributable risk of death associated with smoking is double among HIV patients compared to matched population controls. ${ }^{9}$

\section{Efficacy of smoking cessation in PLWH}

Given the high prevalence and severe health consequences of smoking among HIV+ individuals, identifying smoking cessation interventions for this population with demonstrated efficacy is essential. In 2008, the US Public Health Service Guideline for Treating Tobacco Use and Dependence called for cessation treatment studies tailored to the complex needs of persons who are $\mathrm{HIV}+$, recognizing that interventions tested in the general population may not be efficacious. ${ }^{41}$ Substantial evidence exists to support the efficacy of smoking cessation interventions among smokers in the general population..$^{42,43}$ A burgeoning of smoking cessation studies with persons who are HIV+ have been published in the last decade, although research in this area is still in its infancy. Identifying the currently available research on cessation interventions for HIV+ individuals, as well as the gaps and effective strategies, is important to inform future research and policy efforts to advance the field. Building on previously published reviews, ${ }^{446}$ we synthesize existing research on smoking cessation intervention studies with HIV+ individuals.

Our literature search consisted of using the following databases and search engines: PubMed, PsychINFO, Cochrane Controlled Trials Register, Cochrane Database of Systematic Reviews, and Google Scholar. Search terms used included: smoking cessation, tobacco use cessation, nicotine replacement therapy, bupropion, varenicline, smok*, quit*, HIV $^{*}$, HIV infection, and AIDS. We also performed a manual search of reference lists in selected articles. Our literature search yielded 17 smoking cessation studies among HIV+ persons. The studies represented seven randomized and ten non-randomized designs, and the majority of studies implemented interventions with counseling, motivational strategies, and self-help materials and referrals combined with pharmacological interventions such as nicotine replacement therapy (NRT). The non-pharmacological interventions were delivered by a range of health care professionals, including nurses, physicians, social workers, health educators and peers, and utilized a variety of modalities (for example, individual, group, phone, and Internet). In Table 1, we summarize the study designs and outcomes by type of intervention, including: behavioral interventions $(\mathrm{N}=2)$, pharmacotherapy interventions ( $\mathrm{N}=1)$, and combined interventions $(\mathrm{N}=14)$. Although this review focuses on the primary outcomes 


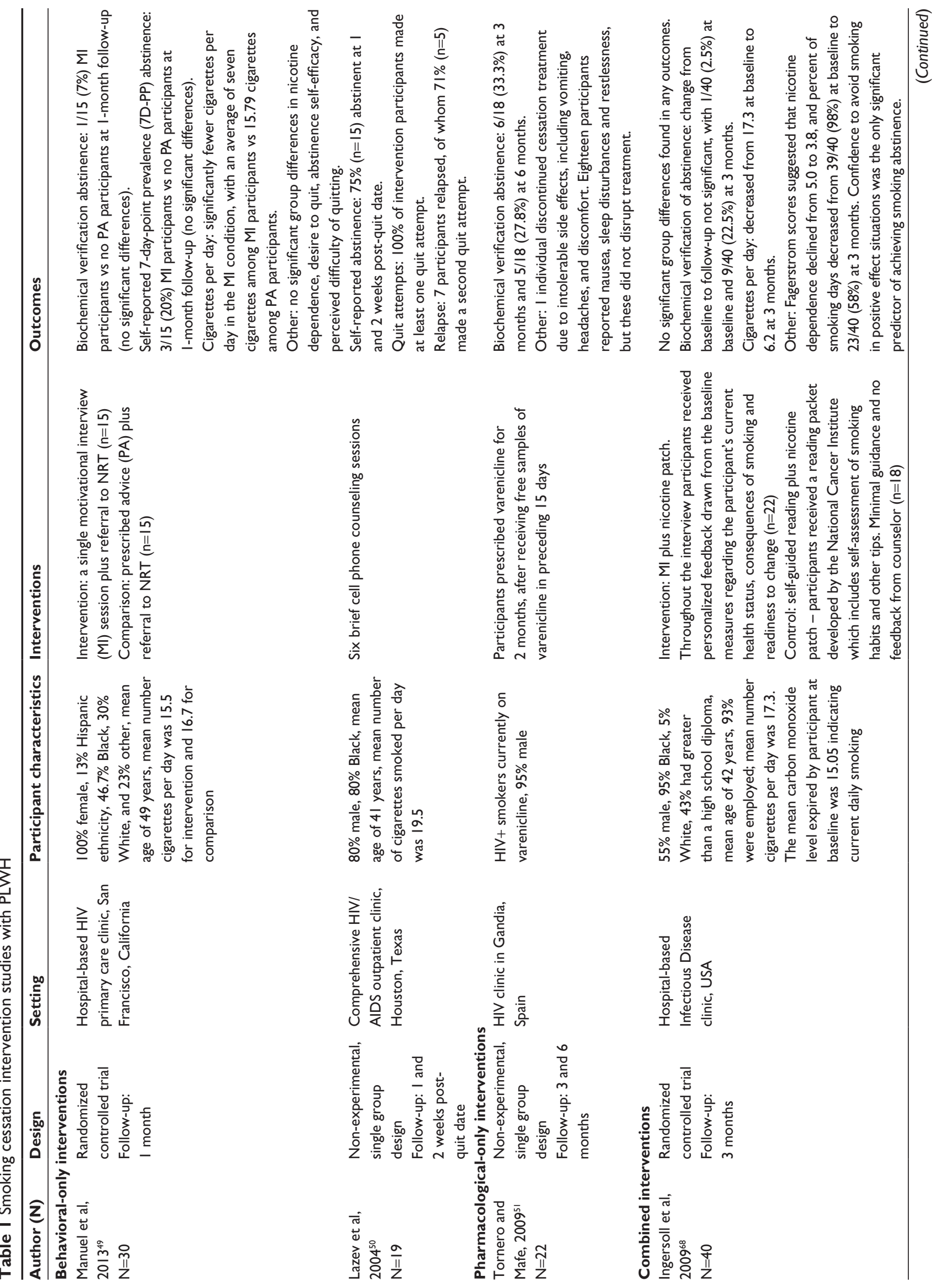




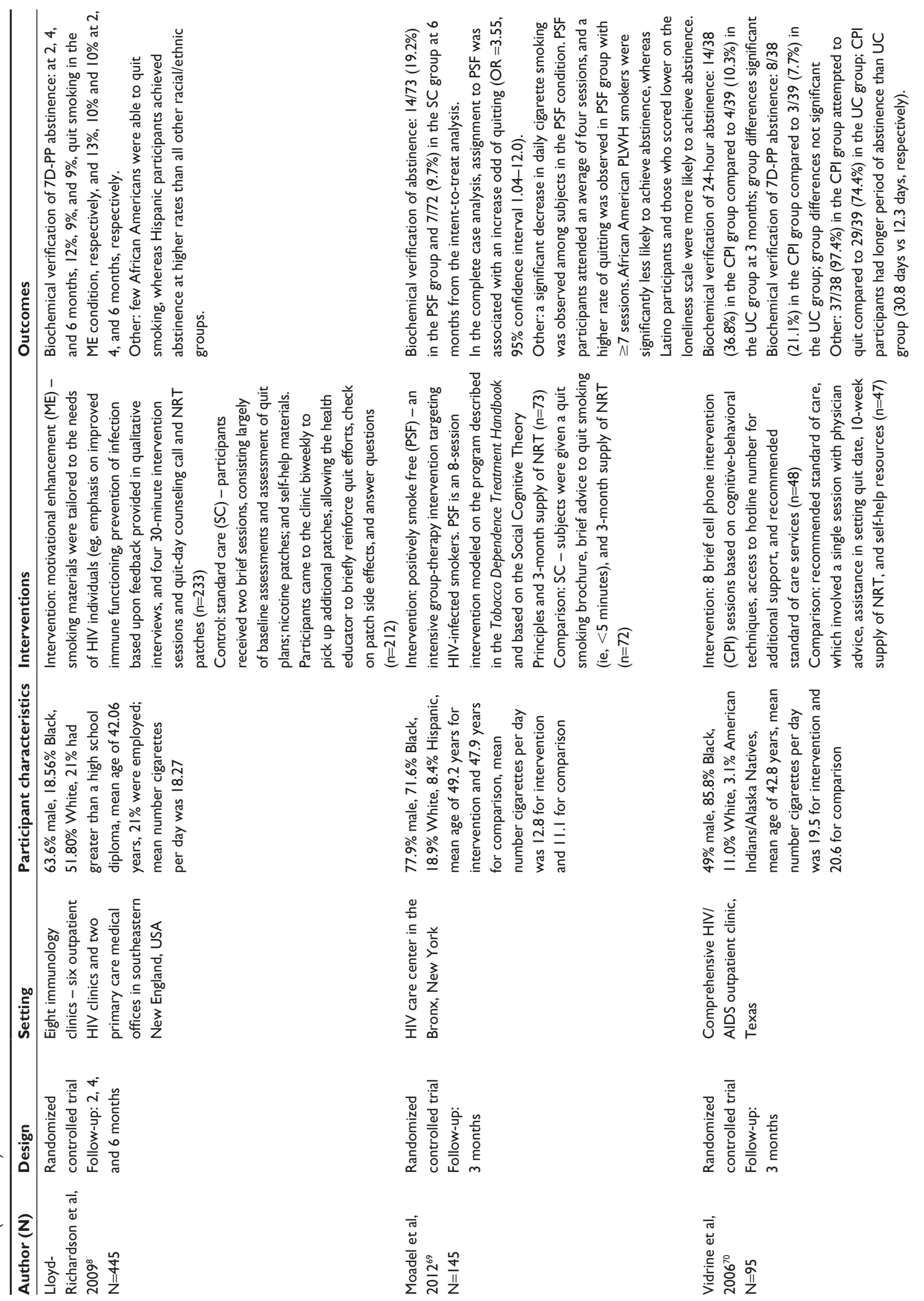




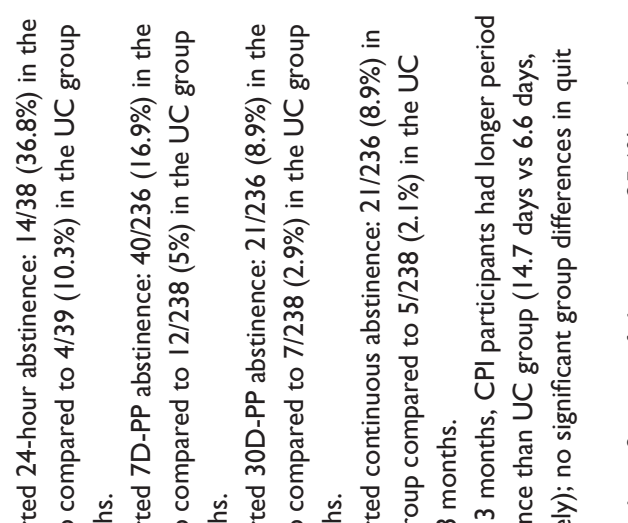

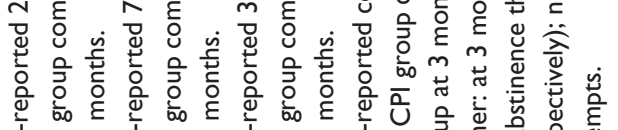

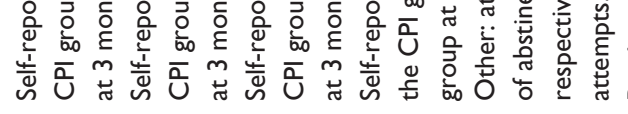
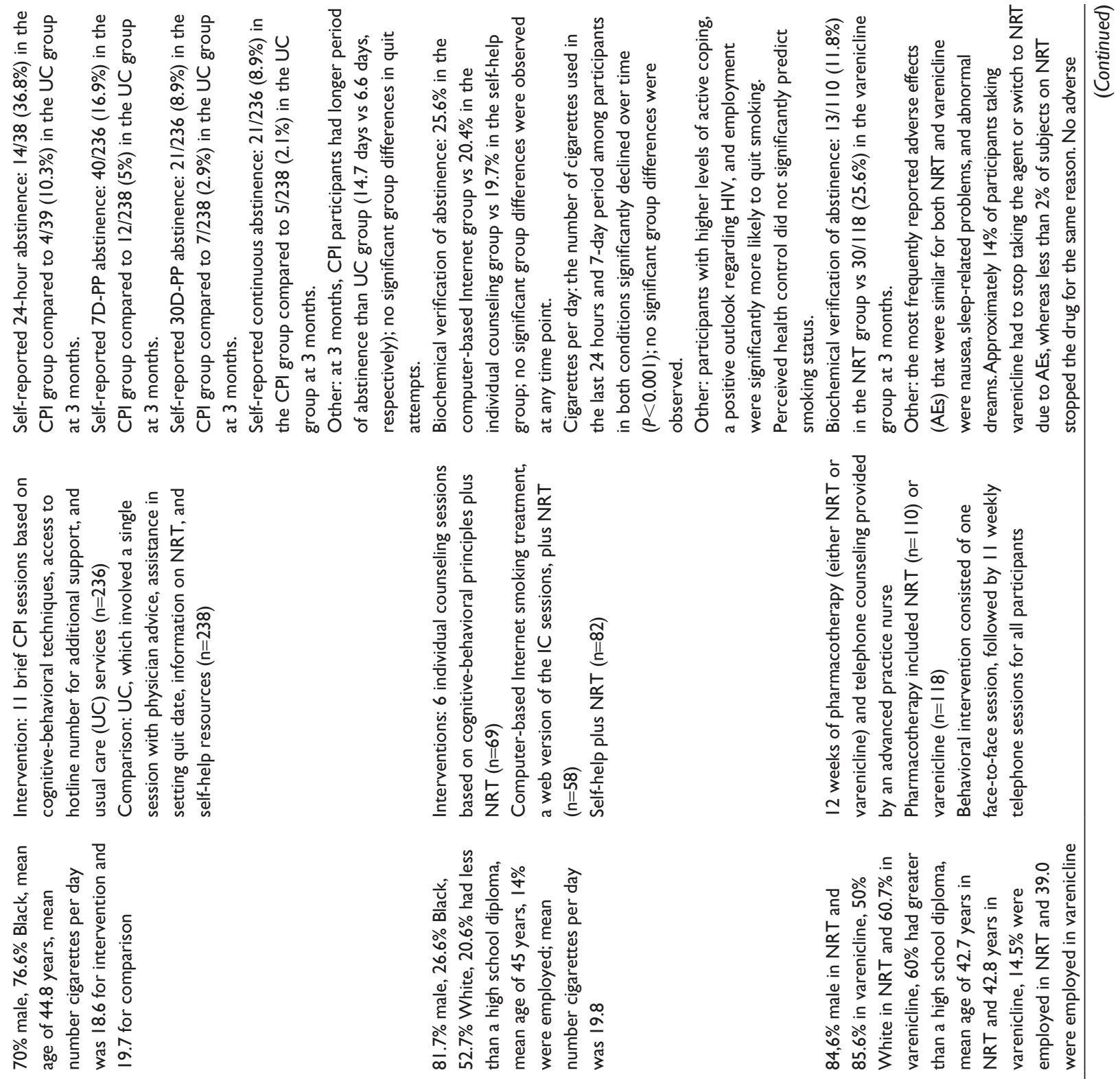

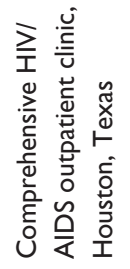
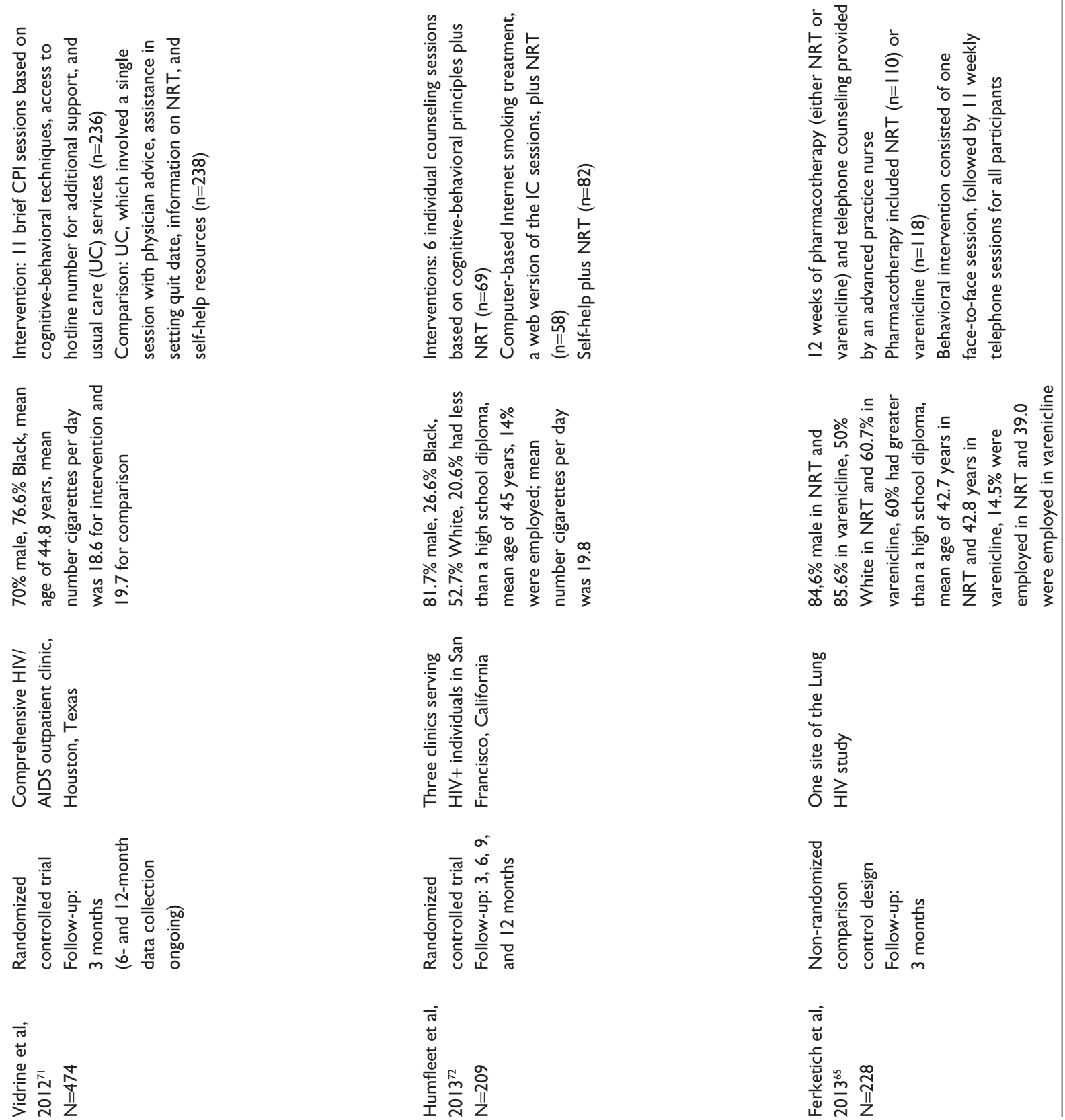

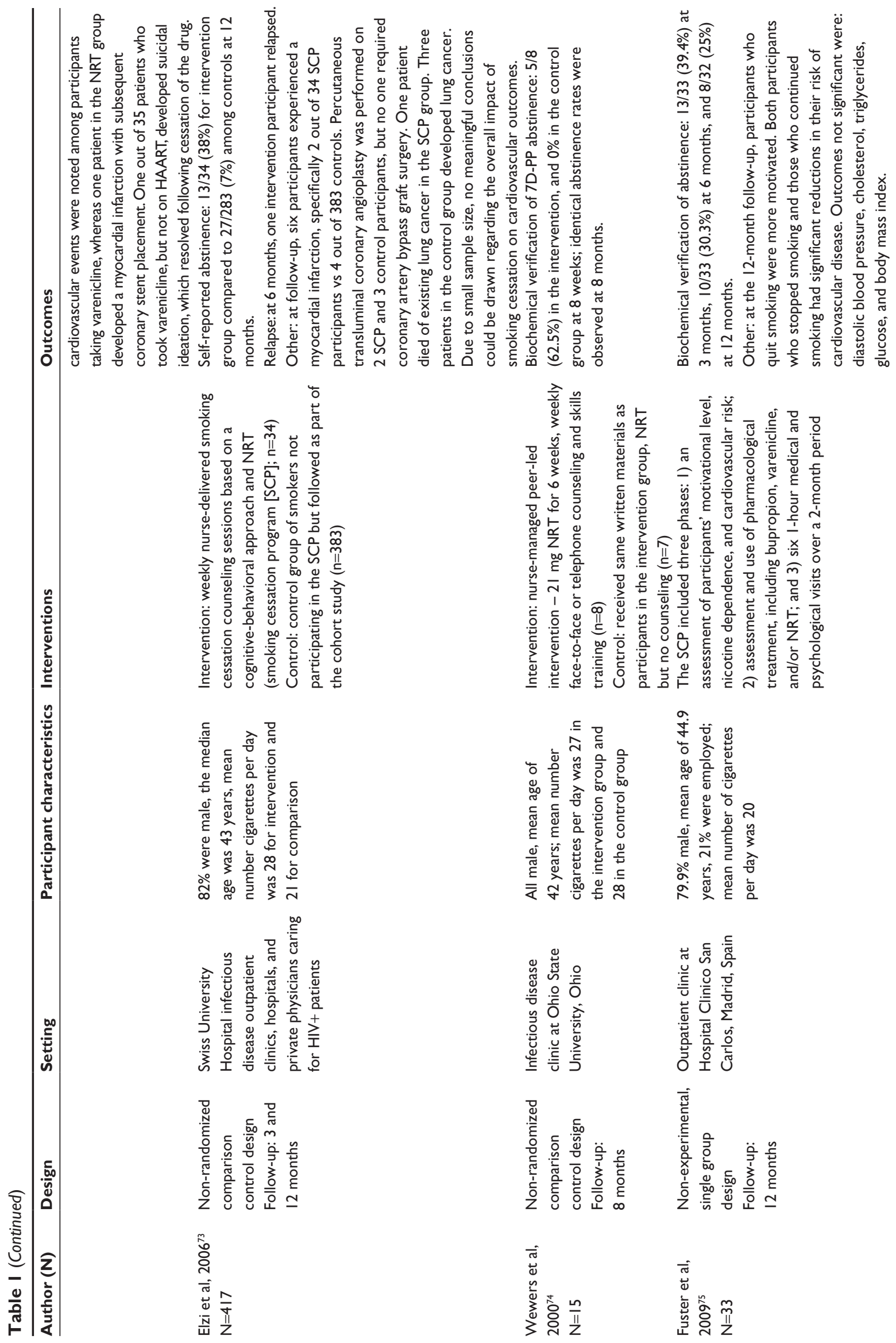

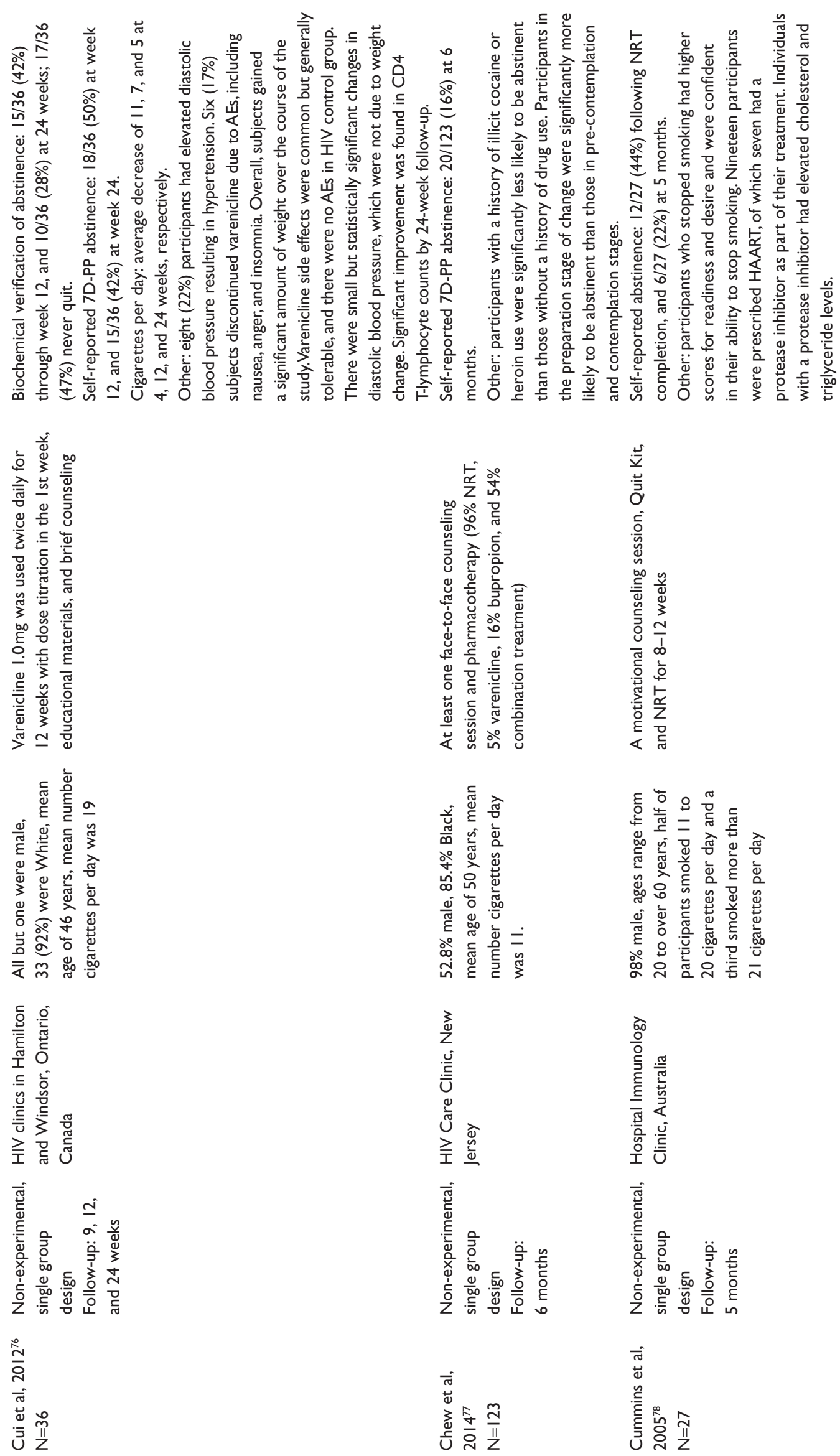


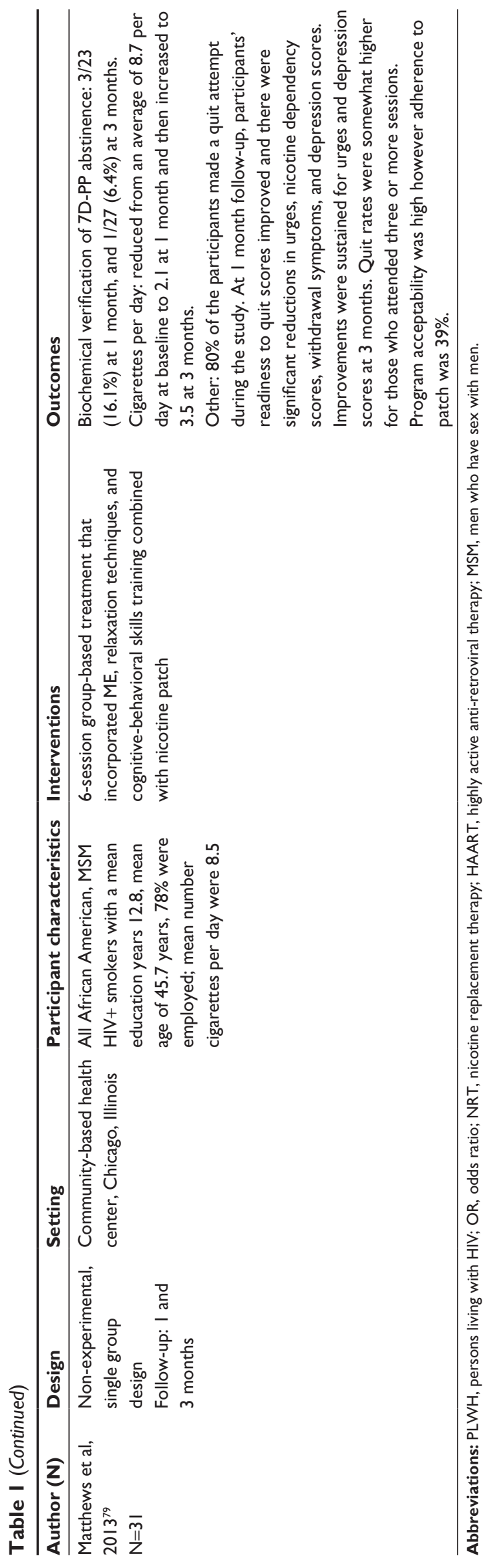

involving smoking cessation rates and smoking abstinence, additional outcomes are also presented in Table 1.

\section{Behavioral interventions}

Behavioral smoking cessation interventions generally include a range of individual, group, online quit programs, cell phone, or telephone counseling. The US Public Health Service Guideline suggests that health care providers use the five A's model of treating tobacco use and dependence. ${ }^{41}$ The components of the model include asking about tobacco use, advising to quit, assessing willingness to quit, assisting in a quit attempt by using cognitive-behavioral techniques and social support strategies, and arranging follow-up visits with the provider. Cognitive-behavioral techniques include problem solving and skills training to help individuals identify triggers to smoking, coping strategies, and education about smoking cessation. In the general population, longer cessation interventions of 10 minutes or more have a higher abstinence rate than briefer interventions of 3 minutes or less. ${ }^{41,47,48}$ Our literature search produced two small-scale behavioral-focused smoking cessation intervention studies with HIV+ smokers.

A cohort of $30 \mathrm{HIV}+$ female smokers was randomized to either a single motivational interview (MI) session or prescribed advice based on the National Cancer Institute's pamphlet, "You Can Quit Smoking". ${ }^{49}$ No significant group differences were found with respect to the primary and most secondary outcomes. A discrepancy between participants' self-reported abstinence and biochemically-verified abstinence prevented clear interpretation of the primary outcomes. While three participants in the MI group self-reported abstinence at follow-up, only one participant's reported abstinence was biochemically verified. Despite this limitation and the small sample, to the authors' knowledge, this was the first randomized controlled trial of MI with HIV+ female smokers.

In a single group design study, 19 of $20 \mathrm{HIV}+$ smokers received six brief cell phone counseling sessions, lasting a minimum of 3 minutes each, over a 2-week period. ${ }^{50}$ All 19 participants made a quit attempt and $75 \%$ achieved abstinence at the 2-week end of treatment. The authors found that using cell phone technology to deliver smoking cessation interventions may address key barriers to accessing services, such as lack of transportation, lack of home telephone service, and a transient living environment.

\section{Pharmacotherapy interventions}

According to the 2008 US Public Health Service Guidelines, HIV+ smokers may use any of the available 
pharmacotherapeutic agents for smoking cessation. ${ }^{41}$ With the exception of one non-randomized study, ${ }^{51}$ the majority of pharmacotherapy interventions implemented with HIV+ smokers have been combined primarily with behavioral or motivational strategies. In the following discussion, we provide a brief overview of available pharmacotherapies for smoking cessation.

NRT works by substituting the nicotine delivered by smoking cigarettes. The various forms of NRT include patches, gum, sublingual tablet or lozenge, and nasal spray or inhaler. No commercially available form of NRT has been shown to be superior to the other, though all forms have been found to be more effective than placebo, with smoking cessation rates increasing by up to $50 \%$ to $70 \%$ among the general population. ${ }^{52}$ Moreover, combination NRT is more effective than single-agent NRT; two clinical trials that investigated the combined use of nicotine patch and inhaler for smoking cessation reported higher success rates with dual agent therapy compared to using either form of NRT. ${ }^{53,54}$

Nicotine electronic cigarettes (e-cigarettes) have gained popularity as they substitute nicotine delivery and ease tobacco withdrawal. Moreover, by direct inhalation, e-cigarettes facilitate nicotine delivery to the lung, and hence the bloodstream. Thus, potentially, they are at least as effective as NRT in aiding smoking cessation. ${ }^{55} \mathrm{~A}$ recently published randomized controlled trial confirmed this hypothesis by finding non-inferiority between e-cigarettes and nicotine patches based on statistically nonsignificant differences in smoking abstinence rates between the two agents. ${ }^{56}$ Even so, quality control issues have been raised about e-cigarettes with regard to variation in smoking characteristics, such as vacuum generation and aerosol density, both between and within brands. ${ }^{57}$ Concern has also been raised about the potentially toxic substances that constitute the vapor from e-cigarettes, although these substances are present in trace amounts and have been deemed an unlikely health hazard. ${ }^{58,59}$ Even so, these safety issues serve as a potential barrier to smoking cessation.

Bupropion and varenicline are the two non-nicotine smoking cessation products approved by the US Food and Drug Administration (FDA). Bupropion sustained release is an aminoketone antidepressant that works by inhibiting dopamine and norepinephrine neuronal uptake as well as blocking nicotinic acetylcholine receptors, thereby attenuating the rewarding effects of nicotine..$^{41}$ Bupropion can also potentiate serotonin levels. Thus, in theory, its co-administration with serotonergic agents such as monoamine oxidase inhibitors may in turn give rise to serotonin syndrome, a life-threatening adverse effect that comprises altered mentation, neuromuscular dysfunction such as hypertonicity or clonus, and autonomic dysregulation such as hyperpyrexia or shivering. In this regard, HAART, specifically protease inhibitors and non-nucleoside reverse transcriptase inhibitors, can inhibit cytochrome P450 enzymes and therefore have the potential to cause serotonin syndrome if combined with the above serotonergic antidepressants. ${ }^{60}$ Other antidepressants with off-label indications for smoking cessation therapy include nortriptyline and venlafaxine, which also inhibit neuronal neurotransmitter reuptake.

Varenicline is a partial nicotinic acetylcholine receptor agonist approved by the FDA for smoking cessation. As an agonist, it attenuates nicotine withdrawal while its antagonistic effect serves to block the nicotinic reinforcing effect, thereby diminishing craving. Multiple randomized controlled trials have reported statistically significant superior efficacy of varenicline in smoking cessation compared to bupropion sustained release, placebo, and transdermal nicotinic transdermal therapy. ${ }^{61-63}$ Among HIV+ smokers, a non-experimental pilot study with 18 participants who were receiving antiretroviral therapy in addition to varenicline for 2 months revealed abstinence after 3 months among six participants (33.3\%) and after 6 months among five participants $(27.8 \%) .{ }^{51}$ Side effects included nausea $(n=5)$ and restlessness and sleep disturbances $(n=6)$, but the side effects did not affect participants' continuation of treatment. The main reason for discontinuation was due to financial hardship.

Notably, the FDA has issued a black box warning for both varenicline and bupropion on serious neuropsychiatric events, including suicidal ideation and depression. In a review article, Kwong and Bouchard-Miller ${ }^{47}$ postulated the exacerbation of these neuropsychiatric symptoms among HIV+ patients taking efavirenz in combination with varenicline or bupropion. A cohort study comprising more than 80,000 patients receiving smoking cessation therapy that compared suicidal behavior among those taking NRT vs varenicline or bupropion concluded that there was no evidence to suggest varenicline increases the risk of suicide or suicidal behavior. ${ }^{64}$ Ferketich et $\mathrm{al}^{65}$ reported similar findings in the largest study to date on the safety profile and effectiveness of varenicline among $\mathrm{HIV}+$ positive smokers. This study is described in more detail under Combined Interventions.

In addition, a recent meta-analysis has raised concern about the potential adverse cardiovascular events associated with varenicline among tobacco users, for example sudden death, congestive heart failure, and arrhythmias. ${ }^{66}$ This suggestion raises even greater concern for HIV+ smokers, 
for whom HIV infection and smoking are independently associated risk factors for cardiovascular disease. ${ }^{24,67}$ The CANQUIT clinical trial is ongoing to further examine the efficacy and side effect profile of varenicline compared to NRT among HIV+ smokers (NCT01800019).

\section{Combined interventions}

The majority of smoking cessation studies with PLWH to date have utilized interventions that have combined pharmacotherapy treatments with a range of counseling or motivational approaches (via individual, group, phone, Internet methods) and self-help resources. Of the 14 combined interventions, six were randomized controlled trials, three were nonrandomized comparison control design studies, and six were non-experimental single group design studies.

In a randomized controlled trial, Ingersoll et $\mathrm{al}^{68}$ examined a combined motivational plus pharmacological intervention among HIV+ smokers. Groups did not differ significantly at 3 months on biochemically-verified abstinence. However, the sample reduced cigarettes per day by half a pack and the percent of smoking days by $41 \%$, and $22 \%$ were abstinent at 3-month follow-up. The authors reported that NRT compliance among HIV+ smokers was a major barrier to successful smoking cessation, and highlighted the importance of implementing strategies to enhance NRT adherence, such as self-guided reading material and booster sessions.

Another randomized study compared smoking cessation rates among HIV+ smokers who received NRT in combination with either standard care (SC) or motivationally enhanced counseling. ${ }^{8}$ The results indicated that the more resourceintensive motivationally enhanced treatment had no additional benefit in smoking cessation rates compared with standard therapy when either was combined with NRT; abstinence rates at 2-month, 4-month and 6-month intervals were $12 \%, 9 \%$, and $9 \%$ respectively in the motivationally enhanced group vs $13 \%, 10 \%$, and $10 \%$ respectively in the SC group. The authors deduced that nicotine patch adherence was enhanced in the SC group by brief bi-weekly "patch pick-up" sessions, during which NRT was supplied while health educators enquired about NRT side effects and responded to questions. Overall, these findings suggest that even brief smoking cessation advice by health care providers may be sufficient to aid quit efforts among HIV+ smokers. Interestingly, in the two studies described above, NRT plus motivational counseling sessions was no more effective than NRT plus brief meetings with a health educator and receipt of self-help quitting materials or NRT plus receipt of self-guided reading about how to quit smoking. 8,68
Moadel et $\mathrm{al}^{69}$ reported findings from $145 \mathrm{HIV}+$ smokers who were randomly assigned to a positively smoking free (PSF) group $(n=73)$ vs SC $(n=72)$. At follow-up, an intent-to-treat analysis showed higher abstinence rates among the PSF group (19.2\%) compared to the control group (9.7\%), but the difference was not significant. The complete case, as-treated analysis showed that PSF participants were significantly more likely to quit smoking than control participants. A significant decrease in daily smoking was observed in PSF participants, with higher quit rates among those who attended seven or more sessions. Participants who self-identified as Latino ethnicity and those with lower loneliness scores were significantly associated with greater abstinence. African American HIV+ participants were less likely to achieve abstinence, suggesting the need for adapted or more tailored treatment strategies for this population.

A randomized trial involving NRT included $95 \mathrm{HIV+}$ current smokers from a large, inner city HIV/AIDS care center and compared smoking cessation treatment outcomes between SC vs proactive cell phone counseling. ${ }^{70}$ These results illustrated significantly higher abstinence rates with cell phone-delivered counseling compared with usual care. Smoking cessation treatment tailored to the special needs of individuals living with HIV/AIDS, such as counseling delivered by cell phone, can significantly increase smoking abstinence rates over that achieved by usual care. In a subsequent study, Vidrine et $\mathrm{al}^{71}$ randomized $474 \mathrm{HIV}+$ smokers to $\mathrm{SC}$ services or a brief cell phone intervention plus usual care. The cell phone intervention group was significantly more likely to achieve point prevalence abstinence at 3 months, but this effect was no longer significant at 6 and 12 months post-intervention. The authors note that they found higher quit rates in the earlier study ${ }^{70}$ compared to the subsequent study. ${ }^{71}$ They attribute the difference to the use of NRT. Due to new clinic rules, participants in the subsequent study were required to make additional clinic visits and attend an information session prior to the distribution of NRT prescriptions. Participants in the earlier study had no such requirements before filling their NRT prescription. These requirements may have served as additional barriers to using NRT.

There is growing support for Internet-based smoking cessation interventions given the low cost in delivering treatment to a potentially large number of people. The majority of research on Internet-based approaches has been conducted with general population smokers with mixed results. ${ }^{42}$ Less is known about the efficacy of Internet-based cessation approaches among HIV+ smokers. Our literature review produced only one study that included an Internet-based 
cessation intervention combined with NRT. Humfleet et $\mathrm{al}^{72}$ compared the efficacy of three smoking cessation interventions provided in HIV clinical treatment settings composed of predominantly male, ethnically/racially diverse, and of low socioeconomic status sample. HIV+ smokers were randomly assigned to one of three conditions in a parallel group design. The study's long-term primary outcomes did not differ significantly between the treatment conditions. However, the number of cigarettes that participants reported smoking in the 24 hours prior to each assessment significantly declined over time. The treatment conditions did not differ in this decline and a similar effect was found when participants were asked about the number of cigarettes in the prior week. The lack of intervention differences were surprising and may be associated with the relatively high quit rates reported by participants in the self-help condition.

Ferketich et $\mathrm{al}^{65}$ conducted a quasi-experimental design study of $228 \mathrm{HIV}+$ smokers in a 12-week regimen of telephone counseling coupled with either varenicline or NRT, followed by biochemical confirmation of smoking abstinence at 3 months. More than two-thirds of the patients in both arms were on HAART, and all participants were preferentially assigned to the varenicline arm unless they were unable or unwilling. The most frequently reported adverse effects in the varenicline arm were nausea, abnormal dreams, and sleep disturbance. Overall, there were no statistically significant differences in the incidence of adverse effects, including mood disorders and suicidal ideation, between participants taking HAART and those who were not taking it. Furthermore, successful smoking abstinence rates were higher in the varenicline group compared to NRT.

Elzi et $\mathrm{al}^{73}$ conducted a secondary analysis of the Swiss HIV Cohort Study, a collaboration of all Swiss University Hospital's infectious disease outpatient clinics, two large cantonal hospitals, smaller hospitals, and physicians caring for HIV+ patients. Data were analyzed on 417 HIV+ individuals participating in face-to-face counseling and NRT delivered by two nurses trained for smoking cessation counseling. After quitting, relapse was prevented by anticipating tempting situations and rehearsing coping strategies. Study results suggested a significantly higher rate of smoking abstinence at 12 months in comparison with observational control individuals.

Using a quasi-experimental design, Wewers et $\mathrm{al}^{74}$ examined the effectiveness of an 8-week, nurse-managed, $\mathrm{HIV}+$ peer-led smoking cessation intervention among HIV+ smokers. At the end of the treatment, $62.5 \%$ of intervention group participants were abstinent from smoking compared with none in the control group. Eight-month abstinence rates were $50 \%$ in the intervention group compared with $0 \%$ in the control group. The nurse-managed and peer-led approach to the intervention was well-received by program participants.

Fuster et $\mathrm{al}^{75}$ recruited $368 \mathrm{HIV}+$ individuals, of whom $63 \%(n=234)$ were active smokers, to participate in a smoking cessation program (SCP) in a hospital outpatient clinic in Madrid, Spain. Of the HIV+ smokers, 33 participated in the program and were followed for 12 months. Approximately $90 \%$ of program participants used pharmacological treatment: $42.4 \%$ bupropion, $24.2 \%$ NRT, and $24.2 \%$ varenicline. At the 3-month follow-up, approximately $39 \%$ of participants had quit smoking. This rate declined over time to $25 \%$ at 12 months. Participants' level of motivation was associated with ceasing smoking.

In a Canadian multicenter open-label pilot study at two regional HIV clinics each subject was offered a package of educational materials and individual face-to-face counseling delivered by a physician or a trained counselor in addition to varenicline. ${ }^{76}$ The study concluded that varenicline appears to be a safe and effective adjunct for smoking cessation among $\mathrm{HIV}+$ patients, together with appropriate counseling.

Chew et $\mathrm{al}^{77}$ reported the results from a prospective cohort study of HIV+ smokers in an SCP in an infectious disease practice with a case-control analysis comparing SCP participants with non-SCP participants. Mean 6-month abstinence rate amongst SCP participants was $16 \%$. A history of cocaine or heroin use was predictive of continued smoking, while smokers in the preparation stage of change were more likely abstinent at 6 months.

Cummins et $\mathrm{al}^{78}$ followed $27 \mathrm{HIV}+$ smokers for 5 months during their participation in an SCP at a hospital immunology clinic in Australia. At the end of the intervention, 44\% of participants ceased smoking and $18 \%$ reduced their nicotine intake. Half of the participants who had ceased started smoking again after 5 months. The results suggested a significant reduction in cardiovascular risk among participants who had stopped smoking at 12 months $(n=8)$.

Matthews et $\mathrm{al}^{79}$ examined the feasibility, acceptability, and outcomes of a culturally tailored smoking cessation intervention for HIV+ African American male smokers recruited from a community-based health center serving primarily lesbian, gay, bisexual, and transgender patients. Eligible smokers were enrolled in a seven-session group-based intervention combined with NRT. Quit rates in the intent-to-treat sample were $16 \%$ at 1 month and $6 \%$ at 3 months. Among participants completing three or more 
sessions, quit rates were somewhat higher $(24 \%$ at 1 month and $10 \%$ at 3 months). Among those participants who did not completely quit smoking, significant reductions in smoking were observed, with fewer daily cigarettes at 1 and 3 months, as compared with baseline. Strengths of the study include systematic development and evaluation of a new treatment manual targeted to an underserved and medically compromised and minority subgroup, obtaining high study completion and retention rates, use of NRT, and the biochemical verification of quit status.

\section{Barriers to implementing smoking cessation interventions}

A number of individual and provider level factors exist that often serve as barriers to implementing smoking cessation interventions and therefore minimize their impact on smoking behavior and other related outcomes. At the individual level, co-occurring mental health needs and alcohol and drug abuse are associated with low success rates in smoking cessation. ${ }^{39}$ For example, HIV+ smokers have reported more symptoms of depression and greater alcohol and drug use than HIV+ non-smokers. ${ }^{80}$ Depression, in particular, is strongly associated with higher nicotine dependence and reduced readiness to stop smoking. ${ }^{5}$ Reisen et $\mathrm{al}^{29}$ found that $66 \%$ of HIV+ smokers reported drinking compared to $56.7 \%$ $\mathrm{HIV}+$ non-smokers. Drug use prevalence for HIV+ smokers and non-smokers were $36.89 \%$ and $22.68 \%$, respectively. In the studies reviewed above, limited attention was given to participants' co-occurring mental health and substance use, despite a significant level of need in the samples. Humfleet et al found a significant relationship between lower mood disturbances and smoking cessation. ${ }^{72}$ In their observational study, Matthews et $\mathrm{al}^{79}$ found a significant decline in depression scores over time following a cognitive-behavioral and motivational enhancement group-based intervention.

In addition, poor adherence to smoking cessation treatments also significantly reduces their impact. ${ }^{81,82}$ In the studies reviewed above, adherence to the behavioral intervention or medication was a common problem. Adherence was particularly problematic for those taking pharmacotherapy. Studies reported medication non-adherence rates ranging from $28 \%$ to $83 \% .^{8,65,68,76,77,79}$ Many HIV+ individuals are taking multiple medications, managing different medication schedules, and dealing with a range of side effects, which often makes adherence difficult. Issues such as mental health, drug abuse, and life stressors are also associated with poor medication adherence among $\mathrm{PLWH}^{83,84}$ and are likely to impact success rates of smoking cessation interventions.
At the provider level, smoking cessation interventions are not routinely integrated into health care settings. Several factors contribute to the lack of attention to smoking cessation among providers. First, health care providers may not feel they can adequately address smoking cessation because of limited familiarity or training in smoking cessation, time constraints during patient visits, or uncertainty in how to manage multiple health problems including smoking. In addition, many PLWH are socioeconomically disadvantaged and may not have the financial resources or insurance to pay for smoking cessation treatment. ${ }^{85,86}$ Other barriers, such as lack of transportation, affect access to smoking cessation interventions. ${ }^{50}$ Increasingly, interventions have tried to address some of these barriers by using cell phone technology ${ }^{50,65,70,71,74}$ or web-based applications. ${ }^{72}$ Race may also play a role in accessing smoking cessation treatment. For example, African American smokers have less access to medical care, are less likely to be assessed for and advised on smoking, and have worse treatment outcomes compared to non-minority populations. ${ }^{87,88}$ In the studies reviewed above, limited attention was given to race/ethnicity and cultural factors. Two studies found poorer smoking outcomes among African American HIV+ smokers. ${ }^{8,69}$ Only one study in this review adapted an existing smoking cessation intervention for African American, MSM individuals who were $\mathrm{HIV}+$, and the findings showed improved smoking cessation outcomes in this vulnerable population. ${ }^{79}$

\section{Discussion}

\section{Analysis of findings}

In the US, the prevalence of smoking among PLWH is roughly thrice that of the general population. From our review, explanations provided to account for this particularly high prevalence rate within the HIV+ population include economic and social marginalization, depression and other mental health comorbidities, a higher incidence of concurrent substance abuse, decreased levels of HRQOL, and a social support network comprised of other smokers.

While the immunological evidence of smoking in the context of HIV infection is both scant and in its nascent stage, the evidence thus far is consistent in associating smoking with further immunosuppression and thus increased susceptibility to opportunistic infections. The point of contention within the literature is whether the resultant cumulative immunosuppression leads to accelerated HIV disease progression and/or whether smoking dose or duration is associated with increased susceptibility to HIV acquisition.

With regard to morbidity and mortality rates among PLWH, the most noteworthy finding was the larger loss of 
life-years associated with smoking than that associated with HIV. That all-cause mortality was halved among those who had quit smoking underscores the importance of prioritizing smoking cessation counseling, as current data indicate that smoking may impact life expectancy considerably more than the HIV infection itself. Yet it can be argued that the success of antiretroviral therapy in extending life expectancy may paradoxically be the underlying cause for the observed trend of long-term tobacco-related sequelae such as chronic lung diseases, and higher non-AIDS mortality rates which are more likely to emerge with prolonged survival. In support of this line of reasoning, the literature reviewed suggests that cigarette smoking effects on all-cause mortality have only recently been observed in studies conducted after the introduction of HAART.

Our review revealed 17 smoking cessation studies with PLWH, of which only seven used randomized designs. Federal guidelines stipulate that PLWH may utilize all FDA-approved medication for smoking cessation. Yet the potential adverse effects of these agents, particularly drug interactions with HAART, have raised interest in their safety profile. Subsequent studies have allayed this issue by demonstrating no statistically significant increase in the incidence of such side effects among HIV+ patients, as is the case for instance with varenicline and neuropsychiatric manifestations. Behavioral techniques that have been studied are centered upon cognitive learning and motivational counseling delivered by a multidisciplinary team using a variety of media including printed literature, online programs, and telephone correspondence. Overall, proactive counseling, defined as more intensive and motivational, is evidently more effective than SC, which solely consists of brief quit advice. In the current review, the strongest evidence supporting the efficacy of smoking cessation among PLWH came from studies that combined behavioral methods with pharmacotherapy. This review found that 14 of the 17 studies used combined interventions, including six randomized controlled studies. A number of limitations and strengths of the reviewed studies are described below, followed by a discussion on recommendations for future research.

\section{Limitations and strengths of reviewed studies}

In this review, all of the randomized controlled studies were conducted in the US and male PLWH made up $70 \%$ to $100 \%$ of the sample populations across the majority of reviewed studies, which limits the generalizability of the studies' findings. Manuel et $\mathrm{al}^{49}$ conducted the only known intervention study tailored to the unique needs of women and found no significant differences between groups on the primary outcome of self-reported 7-day-point prevalence abstinence. However, the study did find significant group differences in favor of the intervention on reducing the average number of cigarettes smoked per day. These mixed results were attributed in part to the small sample size.

Although sample populations were relatively diverse with respect to race and ethnicity, there were few studies that examined racial/ethnic differences in outcomes. Two studies that examined such differences found that African Americans fared more poorly in smoking cessation outcomes compared to other racial and ethnic groups, suggesting that African American HIV+ smokers may have unique needs that are not being addressed by mainstream smoking cessation interventions. ${ }^{8,69}$ Based on our review, Matthews et al have conducted the only known pilot study testing the feasibility of a culturally-adapted smoking cessation intervention for African American MSM PLWH and found promising results, ${ }^{79}$ although a larger trial using a randomized controlled design is warranted to further test the tailored intervention.

This review found a number of barriers, including comorbid mental health needs, alcohol and illicit drug use, financial costs of treatment, lack of adherence to treatment, and lack of transportation, which likely reduced the effectiveness of smoking cessation interventions. Few studies addressed these barriers directly as part of the intervention, highlighting the need for more intense approaches that target these risk factors. Matthews et al found improved depression outcomes during the course of treatment and maintained over the 3-month follow-up. The curriculum used in this study was based on an existing evidence-based intervention that included cognitive-behavioral strategies specifically tailored to the needs of African American, MSM HIV+ smokers. Further study is needed to test the clinical efficacy of the tailored intervention and specific mechanisms by which the intervention is effective. In addition, several studies used phone or Internet-based interventions which can help overcome many barriers to accessing and using traditional interventions, such as lack of transportation, job restrictions, physical disabilities, time, and lack of child care.

Finally, this review highlights the variation of study designs and follow-up intervals, variation in measurement and reporting outcomes, and a lack of information on how the interventions have been tailored to the unique needs of PLWH. In addition, the results across the smoking cessation studies yielded high relapse rates over time. Smokers are most vulnerable to relapse immediately following a quit attempt, 
yet many interventions are not designed to address relapse prevention or do not address it effectively. ${ }^{45}$

Despite these limitations, there were several strengths in the reviewed studies. First, six of the 17 studies used a randomized controlled design. Fourteen studies used strategies that combined pharmacological and behavioral interventions. Twelve studies used biochemical assessments of their smoking outcomes to increase the validity of findings. In addition, six of the studies included technology- or webbased strategies as a way to potentially increase access to smoking cessation interventions. Two studies attempted to address the limitations of prior research by tailoring cessation interventions to the unique needs of HIV+ women and African American MSM smokers.

\section{Recommendations for future research}

Given the importance of smoking cessation among PLWH to general wellbeing and to prolong survival, cessation attempts are likely to be more successful and therapy more effective, if the individual risk factors for smoking within this population are better understood. In our review we identify five risk factors to smoking cessation namely: mental health comorbidity, alcohol and drug use, HRQOL, social networks and supports, and access to smoking cessation treatment. Interestingly, these risk factors are themselves crucial barriers to successfully implementing smoking cessation interventions at all points of the transtheoretical model ("stages of change" model). For instance, depression - a common mental health comorbidity among PLWH - is associated with higher nicotine dependence but also reduced readiness to stop smoking which deleteriously impacts pre-contemplation, contemplation, and preparation stages necessary as per the transtheoretical model for smoking cessation to occur. In addition, co-existing mental health and substance abuse issues present competing priorities for both the health provider and the individual resulting in reduced treatment adherence thus ultimately impacting action, maintenance, and termination stages of change and thus intervention success. This double jeopardy of risk factor and barrier to implementation, needs to be systematically addressed in future studies given the implications for clinical practice and treatment success.

However, we found that some behavioral smoking cessation interventions such as cognitive-behavioral therapy over the telephone were amenable to resolving the identified risk factor of limited access to smoking cessation treatment. Supporting this assertion is evidence to support that as few as six cell phone counseling sessions limited to 3 minutes each over a 2 -week period were sufficient to make a quit attempt with a success rate of $75 \%$ at the end of the 2 -week period. ${ }^{50}$ Though few studies address this particular modality of delivering smoking cessation treatment within the HIV+ population, considering cost-effectiveness, accessibility, convenience, and the success rate of this treatment approach within the general population, integrating telephone-based counseling treatment to smoking cessation treatment protocols is important to consider.

A chief concern with clinical trials is achieving sufficient statistical magnitude of effect or effect size, in order to quantitatively measure the strength of a smoking cessation strategy against other treatment protocols. In order for this to occur we suggest choosing a sample size targeting a particular statistical power, given a pre-specified difference in the hypothesis test. For example, if comparing a pharmacological approach to a cognitive-behavioral approach we may wish to target $80 \%$ power to detect a difference in the effectiveness of each approach, and thus choose a sample size that targets this power. Notably, current smoking cessation literature focused on PLWH is often non-comparative choosing to instead address the merits or demerits of a particular smoking cessation approach within a vacuum, that is, no comparison to similar or different existing cessation strategies. Hence, there is a need for more comparative study of smoking cessation strategies, which addresses magnitude of effect, and thus the potential for clinical effectiveness.

Study design considerations should also address the issue of sample representativeness, which is crucial in determining the generalizability of study results. There is a need for additional studies that adapt interventions to the unique needs of HIV+ smokers and a better understanding of which intervention components are tailored to the target population. Of the 17 studies, only two were tailored specifically for women and African American MSM. ${ }^{49,79}$ In addition, intervention elements that addressed specific risk factors or barriers were not consistently incorporated or disclosed.

Key to bridging the gap between research recommendations and clinical application is the adoption of uniform outcome measures to determine the success of an intervention. Perceptibly, while smoking cessation is the ultimate end point or health outcome, the definition of "smoking cessation" outcome or "smoking abstinence" outcome varies in the literature - eg, "biochemically-verified abstinence" vs "self-reported abstinence". This lack of consistency in measuring and reporting outcomes hampers any additional assessment of comparative effectiveness between smoking cessation interventions and obscures decision-making within the clinical setting. Nevertheless, it is notable that smoking 
cessation intervention studies have increasingly included biochemical verification assessments. A recent systematic review found that six of nine smoking cessation studies with $\mathrm{HIV}+$ smokers used biochemical markers, ${ }^{46}$ while the current review found that 12 studies used biochemical verification assessments.

The length of the follow-up period varied across the reviewed studies, although most included a short follow-up period. Nevertheless, greater uniformity with respect to the length of follow-up would enable providers and researchers to compare across intervention studies and determine which interventions are most effective. While there is no consensus as to an "optimum" length of time to pursue an intervention, examining the long-term effect of interventions is important. Long-term follow-up is particularly important given the deteriorated effectiveness of such programs over time. Such considerations in study design would likely also beneficially influence the accuracy of magnitude of effect, particularly in quantitative assessments of smoking cessation interventions as there would be an appropriate period of time for the desired outcome either to be observed or ruled out as a possibility.

An acknowledged limitation in our review of the literature was the dearth in data regarding maintenance of the smoking cessation outcome. Despite evidence of high relapse rates over time, and right after a quit attempt,${ }^{45}$ the issue of smoking cessation maintenance following an intervention is often neither accounted for in study design nor are steps taken to address relapse prevention. One solution would be to conduct secondary post-study follow-ups to determine maintenance success, and based on these results make recommendations for relapse prevention strategies, such as refresher sessions for cognitive-behavioral therapy or repeating part of or the full smoking cessation intervention.

In our review, the strongest evidence supported the combined interventions that incorporated both behavioral and pharmacological approaches and used randomized controlled study designs. Yet for the purpose of translational research and given finite public health and clinical resources, there is a need to understand the relative contribution of each approach and to determine the extent of interaction between approaches (multiplicative or additive) in supporting smoking cessation outcomes. In particular, there are few comparative studies evaluating the efficacy of pharmacologic-only cessation therapy to behavioral-only interventions vs combined interventions. Such comparative studies would be useful to both policy makers and program managers to best prioritize resources toward the most effective strategies. Moreover, current data on the safety profile of pharmacologic agents are based upon small non-randomized studies, which therefore calls for larger randomized trials. Finally, more research is needed to increase the uptake of smoking cessation interventions in routine practice. Clinicians should receive ongoing encouragement to review the Public Health Service Clinical Guidelines and system decision making guides (available at http://www.ahrq.gov/path/tobacco.htm). In addition, continuing education, in-service trainings, and learning collaboratives may be useful in helping clinicians to consider how to integrate cessation strategies into their regular assessment and treatment of HIV+ clients.

\section{Conclusion}

To reduce the significant burden of tobacco use on PLWH, smoking cessation efforts remain a high priority. Overall, the findings from this review suggest that combined behavioral and pharmacotherapy treatments appear to be beneficial to HIV+ smokers. However, it also highlights the need for additional rigorous research that will advance the field and impact long-term smoking outcomes as well as address other risk factors that contribute to smoking behavior. A future challenge is to develop and test culturally acceptable and effective cessation interventions that address smoking-related health disparities among minority groups and women living with HIV. Incorporating relapse prevention strategies into existing smoking cessation interventions is important to reduce the high rate of smoking relapse in this population. Advances in technology - increased web access, smartphone use, e-cigarettes - offer new challenges as well as opportunities that warrant further exploration. Because smoking is a modifiable risk factor that is associated with significant morbidity and mortality, efforts such as continuing education and training to increase the uptake of smoking cessation interventions into routine HIV services are critical.

\section{Disclosure}

Dr W Kariuki and Dr N Kariuki report a familial relationship between each other. The authors report no other conflicts of interest in this work.

\section{References}

1. Mokdad AH, Marks JS, Stroup DF, Gerberding JL. Actual causes of death in the United States. JAMA. 2004;291:1238-1245.

2. Crothers K, Goulet JL, Rodriguez-Barradas MC, et al. Impact of cigarette smoking on mortality in HIV-positive and HIV-negative veterans. AIDS Educ Prev. 2009;21(3 Suppl):40-53.

3. Lifson AR, Neuhaus J, Arribas JR, van den Berg-Wolf M, Labriola AM, Read TR. Smoking-related health risks among persons with HIV in the strategies for management of antiretroviral therapy clinical trial. Am J Public Health. 2010;100(10):1896-1903. 
4. Tesoriero JM, Gieryic SM, Carrascal A, Lavigne HE. Smoking among HIV-positive New Yorkers: prevalence, frequency, and opportunities for cessation. AIDS Behav. 2010;14(4):824-835.

5. Burkhalter JE, Springer CM, Chhabra R, Ostroff JS, Rapkin BD. Tobacco use and readiness to quit smoking in low-income HIV-infected persons. Nicotine Tob Res. 2005;7(4):511-522.

6. Gritz ER, Vidrine DJ, Lazev AB, Amick BC 3rd, Arduino RC. Smoking behavior in a low-income multiethnic HIV/AIDS population. Nicotine Tob Res. 2004;6(1):71-77.

7. Benard A, Bonnet F, Tessier JF, et al. Tobacco addiction and HIV infection: Toward the implementation of cessation programs. ANRS $\mathrm{CO} 3$ Aquitaine cohort. AIDS Patient Care STDS. 2007;21(7):458-468.

8. Lloyd-Richardson EE, Stanton CA, Papandonatos GD, et al. Motivation and patch treatment for HIV+ smokers: A randomized controlled trial. Addiction. 2009;104(11):1891-1900.

9. Helleberg M, Afzal S, Kronborg G, et al. Mortality attributable to smoking among HIV-1-infected individuals: A nationwide, population-based cohort study. Clin Infect Dis. 2013;56(5):727-734.

10. Centers for Disease Control and Prevention. Best practices for comprehensive tobacco control programs - 2007. Atlanta, GA: National Center for Chronic Disease Prevention and Health Promotion, Office of Smoking and Health; 2007. Available from: ftp://ftp.cdc.gov/pub/ fda/fda/BestPractices_Complete.pdf. Accessed October 25, 2015.

11. US Department of Health and Human Services. How tobacco smoke causes disease: The biology and behavioral basis for smoking-attributable disease: A report of the surgeon general. USDHHS, Centers for Disease Control and Prevention, National Center for Chronic Disease Prevention and Health Promotion, Office on Smoking and Health; 2010. Available from: http://www.cdc.gov/ tobacco/data_statistics/sgr/2010/. Accessed October 25, 2015.

12. Burns DN, Kramer A, Yellin F, et al. Cigarette smoking: a modifier of human immunodeficiency virus type 1 infection? J Acquir Immune Defic Syndr. 1991;4(1):76-83.

13. Zhao L, Li F, Zhang Y, et al. Mechanisms and genes involved in enhancement of HIV infectivity by tobacco smoke. Toxicology. 2010;278(2):242-248.

14. Marshall MM, McCormack MC, Kirk GD. Effect of cigarette smoking on HIV acquisition, progression, and mortality. AIDS Educ Prev. 2009;21(3 Suppl):28-39.

15. Royce RA, Winkelstein W Jr. HIV infection, cigarette smoking and CD4 T-lymphocyte counts: Preliminary results from the San Francisco men's health study. AIDS. 1990;4(4):327-334.

16. Feldman JG, Minkoff H, Schneider MF, et al. Association of cigarette smoking with HIV prognosis among women in the HAART era: a report from the women's interagency HIV study. Am J Public Health. 2006;96(6):1060-1065.

17. Valiathan R, Miguez MJ, Patel B, Arheart KL, Asthana D. Tobacco smoking increases immune activation and impairs T-cell function in HIV infected patients on antiretrovirals: A cross-sectional pilot study. PLoS One. 2014;9(5):e97698.

18. Luu HN, Amirian ES, Scheurer ME. The interaction between smoking status and highly active antiretroviral therapy (HAART) use on the risk of kaposi's sarcoma (KS) in a cohort of HIV-infected men. Br J Cancer. 2013;108(5):1173-1177.

19. Hoover DR, Black C, Jacobson LP, et al. Epidemiologic analysis of kaposi's sarcoma as an early and later AIDS outcome in homosexual men. Am J Epidemiol. 1993;138(4):266-278.

20. Daling JR, Madeleine MM, Johnson LG, et al. Human papillomavirus, smoking, and sexual practices in the etiology of anal cancer. Cancer. 2004;101(2):270-280.

21. Clifford GM, Polesel J, Rickenbach M, et al. Cancer risk in the swiss HIV cohort study: Associations with immunodeficiency, smoking, and highly active antiretroviral therapy. $J$ Natl Cancer Inst. 2005;97(6):425-432.

22. Palefsky JM, Minkoff H, Kalish LA, et al. Cervicovaginal human papillomavirus infection in human immunodeficiency virus-1 (HIV)-positive and high-risk HIV-negative women. J Natl Cancer Inst. 1999;91(3): 226-236.
23. Brockmeyer N, Kreuter A, Pfister H, Altmeyer P, Wieland U. Elevated anal HPV16 DNA loads in HIV+ men who smoke. Paper presented at: The 14th conference on retroviruses and opportunistic infections; February 2007. Fourteenth Conference on Retroviruses and Opportunistic Infections, Los Angeles, abstract 872, 2007.

24. Vidrine DJ. Cigarette smoking and HIV/AIDS: Health implications, smoker characteristics and cessation strategies. AIDS Educ Prev. 2009;21(3 Suppl):3-13.

25. Pence BW, Miller WC, Whetten K, Eron JJ, Gaynes BN. Prevalence of DSM-IV-defined mood, anxiety, and substance use disorders in an HIV clinic in the southeastern united states. J Acquir Immune Defic Syndr. 2006;42(3):298-306.

26. Michel L, Carrieri MP, Fugon L, et al. Harmful alcohol consumption and patterns of substance use in HIV-infected patients receiving antiretrovirals (ANRS-EN12-VESPA study): relevance for clinical management and intervention. AIDS Care. 2010;22(9): $1136-1145$.

27. Shuter J, Bernstein SL, Moadel AB. Cigarette smoking behaviors and beliefs in persons living with HIV/AIDS. Am J Health Behav. 2012; 36(1):75-85.

28. Mdodo R, Frazier EL, Dube SR, et al. Cigarette smoking prevalence among adults with HIV compared with the general adult population in the United States. Ann Intern Med. 2015;162(5):335-348.

29. Reisen CA, Bianchi FT, Cohen-Blair H, et al. Present and past influences on current smoking among HIV-positive male veterans. Nicotine Tob Res. 2011;13(8):638-645.

30. Bryant VE, Kahler CW, Devlin KN, Monti PM, Cohen RA. The effects of cigarette smoking on learning and memory performance among people living with HIV/AIDS. AIDS Care. 2013;25(10): $1308-1316$

31. Durazzo TC, Rothlind JC, Cardenas VA, Studholme C, Weiner MW, Meyerhoff DJ. Chronic cigarette smoking and heavy drinking in human immunodeficiency virus: consequences for neurocognition and brain morphology. Alcohol. 2007;41(7):489-501.

32. Cui Q, Carruthers S, McIvor A, Smaill F, Thabane L, Smieja M. Effect of smoking on lung function, respiratory symptoms and respiratory diseases amongst HIV-positive subjects: a cross-sectional study. AIDS Res Ther. 2010;7:6.

33. van Zyl-Smit RN, Brunet L, Pai M, Yew W. The convergence of the global smoking, COPD, tuberculosis, HIV, and respiratory infection epidemics. Infect Dis Clin North Am. 2010;24(3):693-703.

34. Petrache I, Diab K, Knox KS, et al. HIV associated pulmonary emphysema: A review of the literature and inquiry into its mechanism. Thorax. 2008;63(5):463-469.

35. Palacios R, Pascual J, Cabrera E, et al. Lung cancer in HIV-infected patients. Int J STD AIDS. 2014;25(4):239-243.

36. Triant VA. HIV infection and coronary heart disease: an intersection of epidemics. J Infect Dis. 2012;205 Suppl 3:S355-S361.

37. Bekele T, Rourke SB, Tucker R, et al. Direct and indirect effects of perceived social support on health-related quality of life in persons living with HIV/AIDS. AIDS Care. 2013;25(3):337-346.

38. Degroote S, Vogelaers D, Vandijck D. What determines health-related quality of life among people living with HIV: an updated review of the literature. Arch Public Health. 2014;72(1):40.

39. Rahmanian S, Wewers M, Koletar S, Reynolds N, Ferketich A, Diaz P. Cigarette smoking in the HIV-infected population. Proc Am Thorac Soc. 2011;8(3):313-319.

40. Turner J, Page-Shafer K, Chin DP, Osmond D, Mossar M, Markstein L, Huitsing J, Barnes S, Clemente V, Chesney M. Adverse impact of cigarette smoking on dimensions of health-related quality of life in persons with HIV infection. AIDS Patient Care STDS. 2001;15(12):615-624.

41. US Department of Health and Human Services. Treating tobacco use and dependence: 2008 update. Clinical practice guideline. Rockville, MD: US Department of Health and Human Services; 2008.

42. Ciccolo JT, Busch AM. Behavioral interventions to enhance smoking cessation: A summary of current evidence. Am J Lifestye Med. 2014;9:92-104. 
43. Lancaster T, Stead LF. Individual behavioral counselling for smoking cessation. Cochrane Database Syst Rev. 2005;18(2):CD001292.

44. Nahvi S, Cooperman NA. Review: the need for smoking cessation among HIV-positive smokers. AIDS Educ Prev. 2009; 21(3 Suppl):14-27.

45. Niaura R, Chander G, Hutton H, Stanton C. Interventions to address chronic disease in HIV: Strategies to promote smoking cessation among HIV-infected individuals. Curr HIV/AIDS Rep. 2012;9(4):375-384.

46. Moscou-Jackson G, Commodore-Mensah Y, Farley J, DiGiacomo M. Smoking-cessation interventions in people living with HIV infection: A systematic review. J Assoc Nurses AIDS Care. 2014;25(1):32-45.

47. Kwong J, Bouchard-Miller K. Smoking cessation for persons living with HIV: A review of currently available interventions. JAssoc Nurses AIDS Care. 2010;21(1):3-10.

48. Reus VI, Smith BJ. Multimodal techniques for smoking cessation: a review of their efficacy and utilisation and clinical practice guidelines. Int J Clin Pract. 2008;62(11):1753-1768.

49. Manuel JK, Lum PJ, Hengl NS, Sorensen JL. Smoking cessation interventions with female smokers living with HIV/AIDS: A randomized pilot study of motivational interviewing. AIDS Care. 2013;25(7):820-827.

50. Lazev A, Vidrine D, Arduino R, Gritz E. Increasing access to smoking cessation treatment in a low-income, HIV-positive population: the feasibility of using cellular telephones. Nicotine Tob Res. 2004;6(2): 281-286.

51. Tornero C, Mafe C. Varenicline and antiretroviral therapy in patients with HIV. J Acquir Immune Defic Syndr. 2009;52(5):656.

52. Stead LF, Perera R, Bullen C. Nicotine replacement therapy for smoking cessation. Cochrane Database Syst Rev. 2012;11:CD000146.

53. Bohadana A, Nilsson F, Rasmussen T, Martinet Y. Nicotine inhaler and nicotine patch as a combination therapy for smoking cessation: a randomized, double-blind, placebo-controlled trial. Arch Intern Med. 2000;160(20):3128-3134

54. Westman E, Tomlin K, Rose J. Combining the nicotine inhaler and nicotine patch for smoking cessation. Am J Health Behav. 2000;24(2): 114-119.

55. Etter JF. Electronic cigarettes: a survey of users. BMC Public Health. 2010;10:231

56. Bullen C, Howe C, Laugesen M, et al. Electronic cigarettes for smoking cessation: A randomized controlled trial. Lancet. 2013;382(9905): 1629-1637.

57. Trtchounian A, Williams M, Talbot P. Conventional and electronic cigarettes (e-cigarettes) have different smoking characteristics. Nicotine Tob Res. 2010;12(9):905-912.

58. Goniewicz ML, Knysak J, Gawron M, et al. Levels of selected carcinogens and toxicants in vapour from electronic cigarettes. Tob Control. 2014;23(2):133-139.

59. Burstyn I. Peering through the mist: Systematic review of what the chemistry of contaminants in electronic cigarettes tells us about health risks. BMC Public Health. 2014;14:18.

60. DeSilva KE, Le Flore DB, Marston BJ, Rimland D. Serotonin syndrome in HIV-infected individuals receiving antiretroviral therapy and fluoxetine. AIDS. 2001;15(10):1281-1285

61. Aubin HJ, Bobak A, Britton JR, et al. Varenicline versus transdermal nicotine patch for smoking cessation: results from a randomised openlabel trial. Thorax. 2008;63(8):717-724.

62. Gonzales D, Rennard SI, Nides M, et al. Varenicline, an alpha4beta2 nicotinic acetylcholine receptor partial agonist, vs sustained-release bupropion and placebo for smoking cessation: A randomized controlled trial. JAMA. 2006;296(1):47-55.

63. Jorenby DE, Hays JT, Rigotti NA, et al. Efficacy of varenicline, an alpha4beta2 nicotinic acetylcholine receptor partial agonist, vs placebo or sustained-release bupropion for smoking cessation: A randomized controlled trial. JAMA. 2006;296(1):56-63.

64. Gunnell D, Irvine D, Wise L, Davies C, Martin RM. Varenicline and suicidal behaviour: a cohort study based on data from the general practice research database. $B M J .2009 ; 339: \mathrm{b} 3805$.
65. Ferketich AK, Diaz P, Browning KK, et al. Safety of varenicline among smokers enrolled in the lung HIV study. Nicotine Tob Res. 2013;15(1): $247-254$.

66. Singh S, Loke YK, Spangler JG, Furberg CD. Risk of serious adverse cardiovascular events associated with varenicline: A systematic review and meta-analysis. CMAJ. 2011;183(12):1359-1366.

67. Lip Shultz SE, Mas CM, Henkel JM, Franco VI, Fisher SD, Miller TL. HAART to heart: Highly active antiretroviral therapy and the risk of cardiovascular disease in HIV-infected or exposed children and adults. Expert Rev Anti Infect There. 2012;10(6):661-674.

68. Ingersoll KS, Crapsey KL, Heckman CJ. A test of motivational plus nicotine replacement interventions for HIV positive smokers. AIDS Behav. 2009;13(3):545-554.

69. Moadel AB, Bernstein SL, Murmelstein RJ, Aronstein JH, Dolce EH, Shuter J. A randomized controlled trial of a tailored group smoking cessation intervention for HIV-infected smokers. $J$ Acquir Immune Defic Syndr. 2012;61(2):208-215.

70. Vidrine DJ, Arduino RC, Gritz ER. Impact of a cell phone intervention on mediating mechanisms of smoking cessation in individuals living with HIV/AIDS. Nicotine Tob Res. 2006;8 Suppl 1:S103-S108.

71. Vidrine DJ, Marks RM, Arduino RC, Gritz ER. Efficacy of cell phone-delivered smoking cessation counseling for persons living with HIV/AIDS: 3-month outcomes. Nicotine Tob Res. 2012;14(1): 106-110.

72. Humfleet GL, Hall SM, Bellocchi KL, Dilley JW. A randomized clinical trial of smoking cessation treatments provided in HIV clinical care settings. Nicotine Tob Res. 2013;15(8):1436-1445.

73. Elzi L, Spore D, Voggensperger J, et al. A smoking cessation programme in HIV-infected individuals: A pilot study. Antivir Ther 2006;11(6):787-795.

74. Wewers ME, Needing JL, Kihm KE. The feasibility of a nurse-managed, peer-led tobacco cessation intervention among HIV-positive smokers. $J$ Assoc Nurses AIDS Care. 2000;11(6):37-44.

75. Fuster M, Estrada V, Fernandez-Pinilla MC, et al. Smoking cessation in HIV patients: Rate of success and associated factors. HIV Med. 2009;10(10):614-619.

76. Cui Q, Robinson L, Elston D, et al. Safety and tolerability of varenicline tartrate (Champix $\left({ }^{\circledR}\right) /$ Chantix $\left.\left({ }^{\circledR}\right)\right)$ for smoking cessation in HIVinfected subjects: a pilot open-label study. AIDS Patient Care STDS. 2012;26(1):12-19.

77. Chew D, Steinberg MB, Thomas P, Swaminathan S, Hodder SL. Evaluation of a smoking cessation program for HIV infected individuals in an urban HIV clinic: Challenges and lessons learned. AIDS Res Treat. 2014;2014:237834.

78. Cummins D, Trotter G, Moussa M, Turham G. Smoking cessation for clients who are HIV-positive. Nurs Stand. 2005;20(12):41-47.

79. Matthews AK, Conrad M, Kuhns L, Vargas M, King AC. Project exhale: Preliminary evaluation of a tailored smoking cessation treatment for HIV-positive African American smokers. AIDS Patient Care STDS. 2013;27(1):22-32.

80. Webb MS, Vanable PA, Carey MP, Blair DC. Cigarette smoking among HIV men and women: Examining health, substance use, and psychosocial correlates across the smoking spectrum. J Behav Med. 2007;30(5):371-383.

81. Ingersoll $\mathrm{K}$. The impact of psychiatric symptoms, drug use, and medication regimen on non-adherence to HIV treatment. AIDS Care. 2004;16(2):199-211.

82. Ingersoll KS, Heckman CJ. Patient-clinician relationships and treatment system effects on HIV medication adherence. AIDS Behav 2005;9(1):89-101.

83. Leserman J, Ironson G, O'Cleirigh C, Fordiani JM, Balbin E. Stressful life events and adherence in HIV. AIDS Patient Care STDS. 2008;22(5):403-411.

84. Arnsten JH, Li X, Mizuno Y, et al. Factors associated with antiretroviral therapy adherence and medication errors among HIV-infected injection drug users. J Acquir Immune Defic Syndr. 2007;46 Suppl 2: S64-S71. 
85. Reynolds NR. Cigarette smoking and HIV: More evidence for action. AIDS Educ Prev. 2009;21(3 Suppl):106-121.

86. Humfleet GL, Delucchi K, Kelley K, Hall SM, Dilley J, Harrison G. Characteristics of HIV-positive cigarette smokers: A sample of smokers facing multiple challenges. AIDS Educ Prev. 2009; 21(3 Suppl):54-64.
87. Cox LS, Okuyemi K, Choi WS, Ahluwalia JS. A review of tobacco use treatments in US ethnic minority populations. Am J Health Promot. 2011;25(5 Suppl):S11-S30.

88. Cargill VA, Stone VE. HIV/AIDS: a minority health issue. Med Clin North Am. 2005;89(4):895-912.

\section{Publish your work in this journal}

HIV/AIDS - Research and Palliative Care is an international, peerreviewed open-access journal focusing on advances in research in HIV, its clinical progression and management options including antiviral treatment, palliative care and public healthcare policies to control viral spread. The journal welcomes original research, basic science, clinical \& epidemiological studies, reviews \& evaluations, expert opinion \& commentary, case reports \& extended reports. The manuscript management system is completely online and includes a very quick and fair peer-review system. Visit http://www.dovepress.com/ testimonials.php to read real quotes from published authors. 